\title{
Effect of Plant Growth Regulators on Fruit-set and Quality of Guava
}

\section{Shreef Mahmood*, Mohammad Nazmul Hasan, Sheikh Mohammad Younus Ali, Rafiza Alam Ripa, Mohammad Golap Hossain}

Department of Horticulture, Hajee Mohammad Danesh Science and Technology University, Dinajpur 5200, Bangladesh

\section{A R T I C L E I N F O}

Article history:

Received 24 May 2016

Accepted 10 November 2016

Available online, ISSN: 2148-127X

\section{Keywords:}

Gibberellic acid

$\beta$-naphthoxyacetic acid

Fruit-set

Quality

Guava

A B S T R A C T

\begin{abstract}
Two plant growth regulators: $\beta$-NOA (50 and $80 \mathrm{ppm})$ and GA (200 and $250 \mathrm{ppm})$ were applied to emasculated flowers at anthesis to set parthenocarpic fruit, while in the control treatment fruit set was achieved by natural pollination. The application of $\beta$-NOA found ineffective in setting parthenocarpic guava. No significant differences were observed in the length and diameter of fruit between parthenocarpic and naturally pollinated seeded fruit at different days after anthesis. The mean fruit weight, TSS and ascorbic acid content of parthenocarpic fruit were similar to that of seeded fruit. Significant higher amount of total polyphenol was detected in the seeded fruit than the parthenocarpic fruit. Although $200 \mathrm{ppm}$ GA showed comparatively better response to fruit growth, TSS and ascorbic acid content than $250 \mathrm{ppm}$ GA but not in a statistical level.
\end{abstract}

${ }^{*}$ Corresponding Author:

E-mail: shreefmahmood@yahoo.com

\section{Introduction}

Guava (Psidium guajava L.) is an important fruit throughout the tropics and subtropics due to its delicious taste and high nutritional value. In Bangladesh, guava took the $6^{\text {th }}$ place in respect of area and production of fruits (BBS, 2010). Guava is often referred as the 'Apple of tropics' for its nutritive value. The fruit is rich in vitamin $\mathrm{C}$, which is even 5 times higher than orange (Kumar, 2012). It is also rich in pectin, fiber and different minerals viz., calcium, phosphorus and iron. Apart from vitamin and minerals, it contains high level of powerful antioxidant polyphenols which protect our body from oxidative stress. It has been used as a traditional medicine to treat ulcers, wounds and diarrhea in Phillipines and anorexia, diarrhea, digestive problems, inflammation and ulcers in Brazil (Gutierrez et al., 2008). Moreover, different parts of the tree viz., leaves, bark, and fruit have a long history of medicinal uses. The plant is quite hardy and can grow in the homestead garden even without or little care.

The fruit have high nutritive value and sells at low prices, but is not quite popular to all classes of people, mainly due to its seediness; the seeds being numerous and hard. The number of the seeds varies in different varieties from 300 to 500 per fruit (Shanker, 1967). Therefore, it is important to develop seedless cultivar or to induce seedless fruit by the exogenous application of plant growth regulators (PGRs). The seedless parthenocarpic guava will increase the commercial value of the fruit as those will have no seeds, easy to consume and a minimalwaste. Gustafson (1936) first demonstrated the application of auxin to tomato to set parthenopcarpic fruit. Exogenous application of auxins, gibberellins and cytokinins, or mixtures of those has been reported to induce seedless fruits in eggplant (Olympios, 1976), tomato (Kojima et al., 2003), pepino (Ercan and Akilli, 1996), strawberry (Archbold and Dennis, 1985), grape (Rao et al., 1962) and apple (Costa et al., 2004). In guava, Balasubramanyam and Rangaswamy (1960) and Islam and Siddique (1973) reported that the application of gibberelin induces seedless fruits in guava. However, selection of effective growth regulators, optimal concentrations and spray intervals are vital to induce seedless fruits. Besides, the quality of seedless guava has not been described in details. So the present investigation was formulated to induce seedless guava by PGRs and to determine its physicochemical properties.

\section{Materials and Methods}

\section{Experimental Site}

The experiment was carried out at the Agroforestry farm and Environmental Science, Hajee Mohammad Danesh Science and Technology University, Dinajpur. The experiment was conducted from November 2014 to March 2015.

\section{Plant Material}

Eight years old guava cv. Mukundapuri was chosen in the present investigation. The fruits of this cultivar are pear to round shape, nearly smooth and medium in sized. 
Crop husbandry and crop protection measures were taken according to Bangladesh Agricultural Research Institute (BARI) recommendation.

\section{Application of Plant Growth Regulators}

Individual flowers were tagged on the day of anthesis and in the absence of hormone application the fruits were considered to be formed from natural pollination. To obtain parthenocarpic fruits, anthers were emasculated approximately $24 \mathrm{~h}$ before anthesis to prevent selfpollination, and flowers were then sprayed with the PGR to ensure fruit set. A hand sprayer was used to apply PGR and the flowers were tagged to show the date of application of the PGR. Application of PGR was performed in the morning between 8 to 9 am.

\section{Design of the Experiment}

Two plant growth regulators: Gibberellic acid (GA) and $\beta$-naphthoxyacetic acid (NOA) were used. The concentration i.e., 200 ppm GA, 250 ppm GA, 50 ppm $\beta$ NOA and 80 ppm $\beta$-NOA were applied, while naturally pollinated fruits were the control. The experiment was arranged in the randomized complete block design with four replications. The total numbers of plants were 4, representing 4 replications. For each treatment, 15 fruits were treated as per the experimental design. After fruitset, the diameter and length of the individual fruit were recorded at 30, 60 and 90 days after anthesis (DAA), and also at harvest. To avoid competition among fruits on the same branch only 2 to 3 fruits were allowed to set.

\section{Harvest}

The fruits were harvested at their harvest maturity stage when those were green and medium hard in texture. Fruits were harvested at 110 days after anthesis, starting from mid February until mid March.

\section{Length of Fruit}

The length of fruit was recorded individually from the proximal end of the fruit (site of the calyx) to the distal end (point of abscission of the style) using a meter rule and recorded in centimeters. Length was measured at 30, 60, 90 days after anthesis and at harvest too.

\section{Fruit Diameter}

The diameter of individual fruit was recorded across the widest part of the fruit using an electrical digital caliper (ROHS, Germany) at 30, 60, 90 days after anthesis and at harvest.

\section{Weight of Fruits}

Individual fruit weight was measured in grams at harvest using an electronic balance (G \& G, T100, Germany).

\section{TSS}

Fruits were peeled, and the pericarp (skin) and mesocarp tissues (flesh) were separated. Mesocarp tissue was then gently squeezed and a few drops of juice were used to determine the total soluble solids (TSS) with a digital refractometer (Hanna Instruments, Romania).

\section{Analysis of Ascorbic Acid}

Ascorbic acid content (mg $100 \mathrm{~g}^{-1}$ fresh weight) was determined by the spectrophotometric procedure of Bajaj and Kaur (1981). The absorbance at $760 \mathrm{~nm}$ was measured with a UV/VIS spectrophotometer (PG Instrument Ltd. Model T60, UK). Ascorbic acid concentration was quantified using the standard curve of L-ascorbic acid and expressed as $\mathrm{mg} 100 \mathrm{~g}^{-1}$ fresh weight.

\section{Analysis of Total Phenols:}

Total phenolic compounds were quantified using the Folin-Ciocalteu reagent (FC) and the colorimetric method of Singleton and Rossi (1965). Extraction was performed according to Velioglu et al. (1998) using a homogenizer (VELP Scientifica, Europe). The absorbance was measured at $765 \mathrm{~nm}$ using a UV/VIS spectrophotometer (PG Instrument Ltd. Model T60, UK). Phenol content was estimated from a standard curve of gallic acid and results were expressed as the $\mathrm{mg}$ of gallic acid equivalents (GAE) of $100 \mathrm{~g}^{-1}$ fresh fruit.

\section{Statistical Analysis}

One factor analysis of variance (ANOVA) was conducted for all variables using the Statgraphics Plus Version 2.1 statistical program (STSC, Inc., 1987). The means were compared using Fisher's Least Significant Difference (LSD), while the Student t-test was used to compare pairs of means.

\section{Results and discussion}

In the present investigation, the application of $\beta-\mathrm{NOA}$ (50 and $80 \mathrm{ppm}$ ) failed to set any parthenocarpic fruit of guava. Therefore, the results discussed here refer only to treatments with $200 \mathrm{ppm} \mathrm{GA}, 250 \mathrm{ppm} \mathrm{GA}$ and the control.

\section{Length and Diameter of Fruits}

The length and diameter of fruits were recorded at different DAA until harvest. No significant differences were observed in both the length and diameter of parthenocarpic and seeded fruits at different DAA (Fig. 1). However, the parthenocarpic fruit treated with GA grew rapidly and attained their maximum length and diameter earlier than the seeded fruits of guava. On the other hand, virtually no differences were found in the length and diameter of guava fruits treated with 200 and $250 \mathrm{ppm}$ GA. The length and diameter of both seeded and parthenocarpic fruits showed an initial phase of rapid growth between 30 to 60 DAA followed by a slower increase (Fig. 1). It was also observed that the diameter increased faster than the length in all the treatments. Although fruit induced by 200 ppm GA had a higher length and diameter than $250 \mathrm{ppm}$ GA, however that difference was insignificant (Fig. 1). The patterns of development of seeded and parthenocarpic fruits of guava were similar. However, parthenocarpic fruits showed comparatively faster growth than the seeded ones, so the enlargement of fruits may be due to a result of cell expansion as a result of the application of GA. 

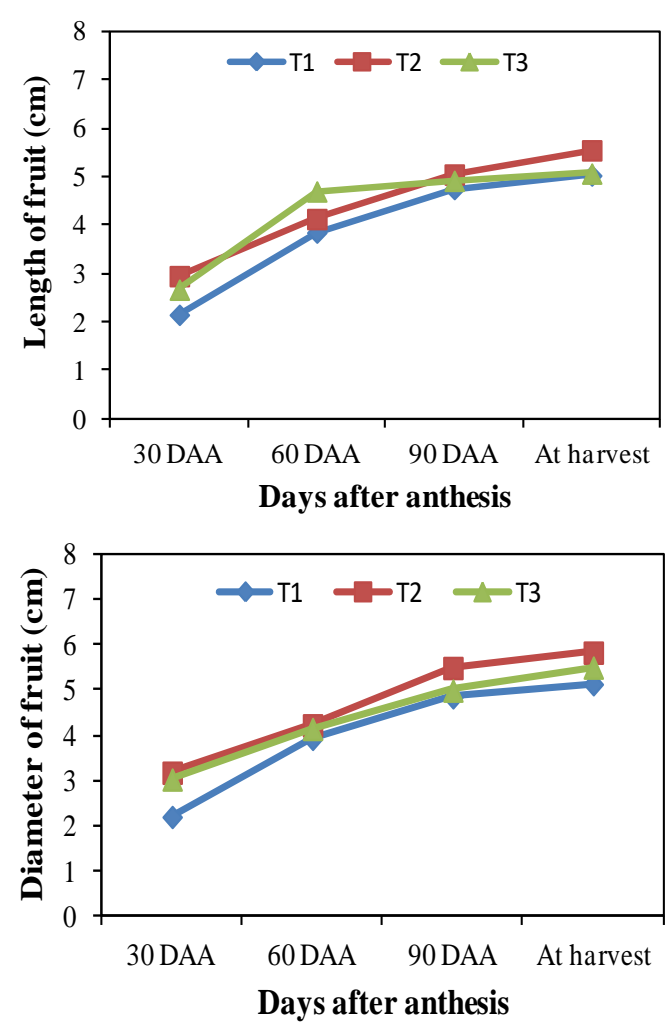

Fig 1 Length (A) and Diameter (B) of fruit of guava cv. Mukundapuri at 30, 60, 90 DAA and at harvest as influenced by natural pollination $(\cdots \cdots), 200 \mathrm{ppm}$ BA (----) and 250 ppm GA (-*-). Vertical bars indicate LSD value according to Fisher's least significant difference test $(\mathrm{P} \leq 0.05)$.

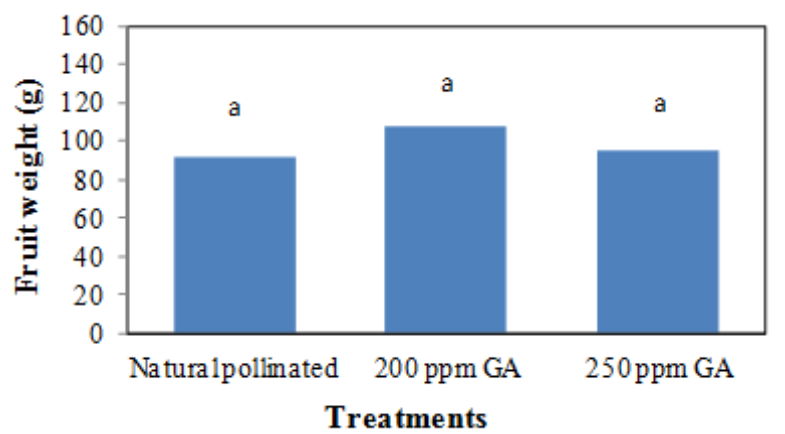

Fig. 2 Mean fruit weight (g) of guava cv. Mukundapuri as influenced by natural pollination, $200 \mathrm{ppm}$ GA and $250 \mathrm{ppm}$ GA. Means of each cultivars accompanied by the same letter are not significantly different according to Fisher's least significant difference test $(\mathrm{P} \leq 0.05)$.

Table 1 Total soluble solid (TSS), ascorbic acid content (mg $100 \mathrm{~g}^{-1}$ ) and total phenol content (mg GAE $100 \mathrm{~g}^{-1}$ fw) in the fruit of guava cv. Mukundapuri produced by natural pollination $\left(\mathrm{T}_{1}\right), 200 \mathrm{ppm}$ GA $\left(\mathrm{T}_{2}\right)$ and $250 \mathrm{ppm}$ GA.

\begin{tabular}{l|ccc}
\hline Treatment & TSS & Ascorbic acid & Total phenol \\
\hline $\mathrm{T}_{1}$ & $10.54 \mathrm{a}$ & $231.62 \mathrm{a}$ & $289.19 \mathrm{a}$ \\
$\mathrm{T}_{2}$ & $11.88 \mathrm{a}$ & $248.55 \mathrm{a}$ & $261.62 \mathrm{~b}$ \\
$\mathrm{~T}_{3}$ & $11.09 \mathrm{a}$ & $244.09 \mathrm{a}$ & $270.09 \mathrm{~b}$ \\
Lsd & 1.74 & 18.24 & 20.13 \\
\hline
\end{tabular}

\section{Weight of Fruits}

The mean weight of individual guava fruit was measured at harvest and GA were found to have no significant effect on fruit weight (Fig. 2). The highest mean fruit weight was $108.23 \mathrm{~g}$ and $91.32 \mathrm{~g}$, respectively in GA induced fruit, whereas the lowest (82.72 g) was in the naturally pollinated fruit. The application of auxin has been shown to increase fruit size of cherry (Stern et al., 2008) and strawberry (Thompson, 1969). The higher mean weight of parthenocarpic fruits apparently results from the promotive effect of GA on fruit growth and development by securing maximum length and diameter compared to the natural pollinated fruits.

\section{Total Soluble Solid (TSS)}

The TSS was measured at harvest and varied significantly between seeded and parthenocarpic fruits, although parthenocapic fruit showed a comparatively higher TSS than the seeded fruits (Table 1). This result is in full accordance with those of Belkbir et al. (1998) who found that NAA did not affect the sugar level of pepper.

\section{Ascorbic Acid Content}

The ascorbic acid content of guava fruit was measured at harvest. It was observed that the seeded fruits have slightly higher ascorbic acid than the fruits treated with 200 and 250 ppm GA, but the differences were statistically insignificant (Table 1). In tomato, Rotino et al. (2005) also did not find any significant difference in ascorbic acid between hybrid 'Alfresh 1000' and the transgenic parthenocarpic tomato $\mathrm{cv}$. 'UG82'. On the contrary, significantly higher ascorbic acid was detected in parthenocarpic guava treated with 200 ppm GA (Islam and Siddique, 1973).

\section{Total Phenolics Content}

The total phenol content of guava fruit was quantified at the middle position of fruit after harvest. The result shows significant differences between seeded and parthenocarpic fruits; higher phenolics was detected in the seeded fruits than the parthenocarpic fruit (Table 1). However, no significant difference was found in the fruits treated with 200 and 250 ppm GA (Table 1). In the present study it is revealed that the total phenolics of the fruit decreased after application of GA. Similarly application of auxin decreased total phenolics in strawberry (Roussos et al., 2009).

\section{Conclusion}

The application of GA at the time of anthesis is beneficial for obtaining parthenocarpic guava, but $\beta$-NOA is ineffective for this purpose. Most of the parameters were not significantly affected by the application of GA except total phnolic content. Though the parthenocarpic guava has no seeds so this fruit will be appreciated much more by the consumers. However, further experiment is needed for the induction of seedless fruit of guava in different cultivars with GA in different seasons. 


\section{Acknowledgement}

The authors acknowledge the Ministry of Science and Technology (MOST) of Bangladesh for financial support to carry out the research work.

\section{References}

Archbold DD, Dennis FG. 1985. Strawberry receptacle growth and endogenous IAA content as affected by growth regulator application and achene removal. J. Am. Soc. Hortic. Sci., 110: 816-820.

Bajaj KL, Kaur G. 1981. Spectrophotometric determination of Lascorbic acid in vegetables and fruits. Analyst., 106: 117-120.

Balasubramanyam VR, Rangaswamy G. 1960. Gibberellins induced parthenocarpy in guava (Psidium guajava L.). Curr. Sci., 28: 312.

BBS. 2010. Year Book of Agricultural Statistics of Bangladesh. Bangladesh Bureau of Statistics. Statistics Division. Ministry of Planning. Govt. of the People's Republic of Bangladesh.

Costa G, Bucchi F, Montefiori M, Bregoli AM, Grappadelli LC. 2004. Thinning activity and fruit quality of Gala and Fuji apple varieties as affected by cytokinins. Acta Hortic., 653: 107-113.

Ercan N, Akilli M. 1996. Reasons for parthenocarpy and the effects of various hormone treatments on fruit set in pepino (Solanum muricatum Ait.). Sci. Hortic., 66: 141-147.

Gustafson FG. 1936. Inducement of fruit development by growthpromoting chemicals. Proceedings of the National Academy of Sciences USA. 22: 628-636.

Gutierrez RMP, Mitchell S, Solis RV. 2008. Psidium guajava: A review of its traditional uses, phytochemistry and pharmacology. J. Ethnopharmacol., 117 (1): 1-27.

Islam MM, Siddique MA. 1973. A study on the induction of parthenocarpic guava by gibberellic acid. Bangladesh Hortic., 1(1): 31-36.
Kojima K, Tamura Y, Nakano M, Han DS, Niimi Y. 2003. Distribution of indole-acetic acid, gibberellin and cytokinins in apoplast and symplast of parthenocarpic tomato fruits. Plant Growth Regul., 41: 99-104.

Kumar A. 2012. Importance for life 'Psidium guava'- review article. Int. J. Res. Pharm. Biomed. Sci., 3(1): 137-143.

Olympios CM. 1976. Effect of plant growth regulators on fruit-set and fruit development of the eggplant (Solanum melongena L.). Hortic. Res., 16: 65-70.

Rao SN, Reddy RN, Sreeramulu P. 1962. Studies on the effects of gibberellic acid on fruit set, size, weight, seed content and quality of grapes. Andhra Agric. J., 9: 166-174.

Rotino GL, Acciarri N, Sabatini E, Mennella G, Lo Scalzo R, Maestrelli A, Molesini B, Pandolfini T, Scalzo J, Mezzetti B, Spena A. 2005. Open field trial of genetically modified parthenocarpic tomato: seedlessness and fruit quality. BMC Biotechnol., 5: 32.

Roussos PA, Denaxa NK, Damvakaris T. 2009. Strawberry fruit quality attributes after application of plant growth stimulating compounds. Sci. Hortic., 119: 138-146.

Shanker S. 1967. Physico-chemical studies of five guava varieties of Uttar Pradesh. Allahabad Farmer, 41(1): 9-12.

Singleton VL, Rossi JA. 1965. Colorimetry of total phenolics with phosphomolybdic phosphotungstic acid reagents. Am. J. Enol. Vitic. 16: 144-158.

Stern RA, Flaishman M, Applebaum S, Ben-Arie R. 2008. Auxins increase fruit size of 'Bing' (Prunus avium L.) cherry in a warm climate. Acta Hortic., 774: 243-249.

STSC Inc., 1987. Statgraphics Users' Guide.

Thompson PA. 1969. The effect of applied growth substances on development of the strawberry fruit. II. Interactions of auxins and gibberellins. J. Exp. Bot., 20: 629-647.

Velioglu YS, Mazza G, Gao L, Oomah BD. 1998. Antioxidant activity and total phenolics in selected fruits, vegetables, and grain products. J. Agr. Food Chem., 46: 4113-4117. 